\title{
Multiorgan failure during COVID-19 pandemic in cardiovascular patients. Role of advanced cardiac and pulmonary support
}

\author{
Fallo multiorgánico durante la pandemia de COVID-19 en pacientes \\ cardiovasculares. Rol de la asistencia circulatoria y pulmonar
}

Alejandro Barbagelata' ${ }^{1}$ Juliana Giorgi ${ }^{2}$, Michael M. Koerner ${ }^{3}$, David A. Baran ${ }^{4}$

\begin{abstract}
COVID-19 has now claimed several thousands of lives and overwhelmed the healthcare systems of several countries. Patients with cardiovascular disease are at particular risk not just of the infection itself but of its cardiac complications. Compared to other hospitalized patients with COVID-19, those needing intensive care, are more likely to have preexisting cardiovascular diseases or risk factors. Cytokine storm with hyperinflammation correlates with the severity of the disease. It is associated with mortality and is a key factor in determining the clinical course of extrapulmonary multiple-organ failure, suggesting that the inflammatory storm is associated with damage in extrapulmonary tissues and organs. Advanced Cardiac and Pulmonary Support has been reported in selected a COVID population.
\end{abstract}

Keywords: COVID-19 pandemia, multiorgan failure, cardiovascular patients, advanced cardiac and pulmonary support.

\begin{abstract}
RESUMEN
La actual pandemia mundial con COVID-19 generó miles de contagios, colapsó los sistemas de salud y generó una elevada mortalidad y consecuencias en la salud pública y la economía de numerosos países. Los pacientes con enfermedad cardiovascular tienen un riesgo particular, no solo mayor propensión a la infección en sí sino también a las complicaciones cardiovasculares. En comparación con otros pacientes hospitalizados con COVID-19, los pacientes cardiovasculares tienen más probabilidades de requerir cuidados intensivos, intubación endotraqueal y entre 5 y 10 veces mayor probabilidad de morir. La respuesta del organismo hacia el virus se hace en algunos casos como hiperinflamación y tormenta de citoquinas para contrarrestar el virus, pero termina atacando a las células de su propio organismo. Este fenómeno se relaciona con la gravedad de la enfermedad y está asociada con compromiso de múltiples órganos, lo que sugiere que la tormenta inflamatoria se asocia con daños en los tejidos y órganos extrapulmonares. La necesidad de asistencia circulatoria y pulmonar es requerida en casos de gravedad y existen reportes que durante la pandemia se utilizó con resultados variables. Debido a que son terapias complejas y de alto costo, es necesario estandarizar su utilización.
\end{abstract}

Palabras claves: COVID-19 pandemia, multiorgan failure, cardiovascular patients, advanced cardiac and pulmonary support.

Revista Argentina de Cardioangiología Intervencionista 2020;11(2):58-64. https://doi.org/10.30567/RACI/202002/0058-0064

\section{INTRODUCTION}

Patients with cardiovascular disease are at particular risk not just of the infection itself but of its cardiac complications. Cytokine storm is associated with mortality and is a key factor in determining the clinical course of extrapulmonary multiple-organ failure. Advanced cardiac and pulmonary support has been applied in selected COVID population

\section{ILLUSTRATIVE CASE REPORT}

A 68-year-old man was hospitalized in Sirio Libanês Hospital (São Paulo, Brazil) after neurosurgical treatment (temporal meningioma removal). At the $5^{\text {th }}$ post-surgical day he started having fever, hypoxia and respiratory failure requiring mechanical ventilation. Chest CT showed a lesion of

1. Universidad Católica Argentina / Duke University School of Medicine

2. Sirio Libanês Hospital São Paulo, Brazil

3. Integris Baptist Medical Center, Oklahoma City, OK, USA

4. Eastern Virginia Medical School (Cardiology) Sentara Heart Hospital, Norfolk VA, USA

$\triangle$ Correspondencia: Alejandro Barbagelata.n.barbagelata@duke.edu / barba001@me.com

Los autores declaran no tener conflictos de intereses.

Recibido:02/06/2020|Aceptado:08/06/2020 right lower lung and diffuse consolidation on both lower lungs. Nasopharyngeal swabs were positive for SARS-CoV-2 (COVID-19) nucleic acid by the fluorescence quantitative RT-PCR. His relevant comorbidities were obesity, hypertension, rheumatoid arthritis, coronary artery disease and prostatic cancer without metastatic lesion. Blood tests revealed

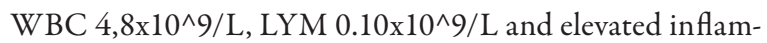
matory markers as D-dimer, ferritin, troponin, lactate dehydrogenase (LDH) $1052 \mathrm{U} / \mathrm{L}$, procalcitonin (PCT) $0.71 \mathrm{ng} /$ $\mathrm{ml}$, C-reactive protein (CRP) $24 \mathrm{mg} / \mathrm{L}$. Blood gas analysis revealed: $\mathrm{pH}$ 7.17, $\mathrm{PO} 271 \mathrm{mmHg}, \mathrm{pCO} 258 \mathrm{mmHg}$ with fraction of inspired oxygen ( $\mathrm{FiO} 2) 100 \%$ and the need of high doses of dobutamine $(20 \mathrm{mcg} / \mathrm{kg} / \mathrm{min})$ and noradrenaline $(0,8 \mathrm{mcg} / \mathrm{kg} / \mathrm{min})$ due to low mean arterial blood pressure of $55 \mathrm{mmHg}$. Echocardiogram showed an acutely reduced ejection fraction of $35 \%$ and estimated pulmonary pressures of $50 \mathrm{mmHg}$. Medical treatment with hydroxychloroquine $400 \mathrm{mg}$, azithromycin $500 \mathrm{mg}$ and methylprednisolone $40 \mathrm{mg}$ was started together with vancomycin, meropenem, fluconazole as coverage in case of a superimposed infection. All these means did not improve his clinical situation. Due to refractory cardiogenic shock with renal and pulmonary failure, percutaneous peripheral Veno-Arterial extracorporeal membrane oxygenation (V-A-ECMO) support (Maquet) was inserted at bedside. A heparin coated cannula (Maquet) was placed into the left femoral artery with a leg reperfusion cannula, and a heparin coated cannu- 
la (Maquet) was placed in the left femoral vein. The hemodynamic and metabolic situation stabilized together with renal replacement therapy and vasoactive drugs could be reduced. The patient also was treated with lopinavir/ritonavir (Kaletra ${ }^{\circ}$, Abbvie $\left.^{\circ}\right)$. The ejection fraction improved to $50 \%$ after 4 days of V-A ECMO support with 2,77 lpm flow. Unfortunately, on the 3rd day after ECMO decannulation septic shock installed as a typical skin COVID-19 necrotizing fasciitis at the previous V-A-ECMO cannulation site. At this time the patient deteriorated due to multiple organ dysfunction and end of life therapy was implemented.

\section{DISCUSSION}

Around 15\% of COVID-19 infected patients could develop severe disease warranting hospital admission, and $5 \%$ are designated as critically ill $^{1}$. Whereas COVID-19 is primarily a respiratory infection, it has important systemic effects including the cardiovascular, coagulation and immune systems $s^{2,3}$. Those with preexisting cardiovascular conditions represent a large proportion with symptomatic infection, and experience disproportionately worse outcomes between a fiveto tenfold increase in mortality ${ }^{2,4}$. Compared to other hospitalized patients with COVID-19, those needing intensive care, are more likely to have preexisting cardiovascular diseases or risk factors ${ }^{5-14}$. In a group of 191 patients, $62 \%$ of those who died were male and of these $30 \%$ had hypertension, $19 \%$ diabetes and $8 \%$ coronary artery disease ${ }^{15}$. In a similar population of 138 hospitalized COVID-19 patients, those requiring intensive care, were older and more likely to have hypertension, diabetes, and cardiovascular or cerebrovascular disease ${ }^{6}$. Italian data likewise show the same trend in older patients having co-morbidities. In a subsample of 355 Italian patients who died with COVID-19, the mean age was 79.5 years: $70 \%$ were men, $30 \%$ had ischemic heart disease, 36\% diabetes, $20 \%$ cancer and $25 \%$ atrial fibrillation $^{13,14,16}$. In the US, Washington state reported that in 21 intensive care patients with COVID-19, the mean age was 70 and $86 \%$ had comorbid conditions including congestive heart failure, chronic kidney disease, and diabetes ${ }^{10}$. A more recent report from New York, showed that of 1,150 adults hospitalized with COVID-19, 257 (22\%) were critically ill with respiratory failure, $79 \%$ of patients received mechanical ventilation during hospitalization for median durations of 27 days among survivors and 10 days among non-survivors. One quarter of intubated patients received early neuromuscular blockade, $17 \%$ received prone positioning ventilation, and $3 \%$ received extracorporeal membrane oxygenation $(\mathrm{ECMO})^{17}$.

\section{Immune System out of control in COVID-19 heralds multiorgan failure}

When SARS-CoV-2 enters a cell to replicate, it can disable or destroy it, leading to the release of potential danger signals to activate the host's immune response. A rapid and well-coordinated innate immune response is the first line of defense against viral infection. The production of Interferon IFN-I or $\alpha / \beta$ is the key natural immune response. It is hypothesized that a delayed release of interferons (IFNs) in the early stages of COVID-19 infection that hinders the body's antiviral response and generate high levels of proinflammatory cytokines [interleukin (IL)-1 $\beta$, IL-6, tumor necrosis factor (TNF) and chemokines $]^{18}$ through elevated serum cytokine and chemokine levels related to the high number of neutrophils and monocytes in the patients lung tissues and peripheral blood. Dysregulated and excessive immune responses may cause immune damage to the human body. The virus eliminates key lymphocytes, particularly CD4+ as coordinator of $\mathrm{T}$ cell function. The lower the lymphocyte count, the worse the outcome ${ }^{2}$. With the immune system partially disabled, the macrophages and then neutrophils come in as a second line with IL- 1 and IL- 6 arriving on the scene particularly in the sickest COVID-19 patients where their blood has high levels of these immune system proteins developing the "cytokine storm" picture where the body starts to attack its own cells and tissues rather than just fighting off the virus ${ }^{2,18}$.

\section{Impending storm ahead}

When biomarkers start rising particularly when CRP, troponin, IL-6, ferritin, D-dimer, creatinine start rising means that there is an impending storm. It means that some of these processes are at play and is particularly important given that many patients with CVD have heightened angiotensin-converting enzyme 2 (ACE2) receptor activity to begin with, making them vulnerable to COVID-19. Those who have higher levels of markers should be followed closely, monitored for arrhythmias, ischemia and organ failure particularly in CV patients, with efforts made to restore immune balance. Intervention will likely need to be instituted early, before the immune amplification process is fully underway. This cytokine storm is associated with disease progression in patients with high levels of IL-1B, IL-2R, IL-6 IFN- $\gamma$, IP10 and monocyte chemoattractant protein 1 (MCP-1 $)^{2}$ and the larger the number of immune cells that results in hyperinflammation correlate with the severity of the disease. In patients with acute respiratory distress syndrome (ARDS) cytokine level increase is positively correlated with mortality rate and is also a key factor in determining the clinical course of extrapulmonary multiple-organ failure, suggesting that the inflammatory storm is associated with damage in extrapulmonary tissues and organs. It also might explain why some people have a severe reaction to coronaviruses while others only experience mild symptoms particularly younger people as their immune systems are less developed and so produce lower levels of inflammation-driving cytokines ${ }^{18}$. Systemic inflammation has long been posited as a trigger for cardiovascular events and the body's potent immune response to COVID-19 poses unique risks to the heart and may result in part from a predilection of COVID-19 for the cardiovascular system, combined with the already widespread prevalence of cardiovascular disease that places patients at high risk of COVID-19 complications ${ }^{19}$. Positive feedback between cardiovascular disease and abnormal immune function might explain the increased risk of death in COVID-19 patients with cardiovascular risk factors ${ }^{7,20}$ Age (especially), diabetes, hypertension and obesity promote immune system dysregulation, while this dysregulation affects cholesterol metabolism and systemic inflammation ${ }^{21}$. Thus elderly patients with cardiovascular disease are especially vulnerable and the presence of cardiovascular risk factors may be a marker of accelerated immunologic aging or dysregulation that increases the likelihood of cardiovascular complications during the infection. The virus uses ACE2 receptors to get into the cell that are highly expressed in the myocardium in addition to the lung and other organs $s^{2,22}$. 
Reports describing fulminant myocarditis confirmed at autopsy by the presence of inflammatory, mononuclear infiltrates, and even the virus itself as shown in an Italian patient with cardiogenic shock ${ }^{23}$ remind us that the heart, and not just the lung, is a target ${ }^{23-26}$. ACE-2 receptors are also present in other organs and systems, including kidneys, eyes, gut, liver, vasculature and central nervous system that might attract inflammatory cytokines and multiorgan failure ${ }^{27}$. Severe COVID-19 infection can damage the heart through direct viral infection but also due to poor oxygenation, hemodynamic stress, hypercoagulability, exacerbation of diabetes and hypertension ${ }^{2,9}$. Elevated troponin or CK-MB levels may result from myocardial ischemia or non-ischemic processes such as myocarditis, and it frequently accompanies severe $^{28}$ COVID-19 infections. Compared to surviving patients, those who die have significantly higher troponin levels, especially when acute respiratory distress syndrome (ARDS) has complicated the picture ${ }^{20}$. Cohort studies from hospitalized patients estimate that myocardial injury occurs in $7-28 \%{ }^{6,7,29-31}$ and is significantly more common in patients admitted to intensive care and in those who died ${ }^{4}$. Even patients without known CV disease can die with elevated troponin levels and cardiac arrest ${ }^{29,32}$. It is clear that several mechanisms can injure the heart which singly or together can present in different ways (Figure 1), depending upon the pre-existing conditions, viral processes, degree of hypoxia, and inflammatory response of the patient ${ }^{32,33}$.

Heart failure and cardiogenic shock can develop in COVID-19 patients. The complexity of these cases and their frequent progression to multiorgan dysfunction can often cloud the "exact" cause of death". Zhou et al. observed heart failure in $23.0 \%$ of COVID-19 patients, and in $52 \%$ of the non-survivors ${ }^{20}$. The report from Washington state noted that $33 \%$ of intensive care patients developed cardiomyopathy ${ }^{10}$. The occurrence of pulmonary edema in COVID-19 infections is another source of clinical confusion, that is, whether it is non-cardiogenic (ARDS), cardiogenic, or both. It is important to distinguish these entities when managing the respiratory manifestations of COVID-19. Right heart catherization has been discouraged, as ICU physician trend to use the Berlin criteria for $\mathrm{ARDS}^{34}$ and volume status can be assessed with serum brain natriuretic peptide levels and cardiac echocardiography ${ }^{35}$. Still, pulmonary artery catheterization may be considered as different management strategy for ARDS and left heart failure.

Arrhythmia, venous thromboembolism, strokes and skin lesions are also frequent complication in multiorgan failu$\mathrm{re}^{36-38}$. The appearance of a new or marked worsening of an existing arrhythmia can result from the metabolic, neurohormonal, and inflammatory stress of COVID-19 infection in patients with or without cardiovascular disease $\mathrm{e}^{39}$ in particular malignant tachyarrhythmia appear in the setting of elevated troponin or myocarditis ${ }^{40}$. Most COVID patient may be at risk of arrhythmias caused by medication, electrolyte disorders, or both. Therapy combining hydroxychloroquine plus azithromycin can prolong QT-interval and generate fatal arrhytmias ${ }^{41}$. A 2000 patients NIH trial is underway to test safety and efficacy of this combination ${ }^{42}$. Recently a large multinational cohort study showed no benefit mainly due to arrhythmias ${ }^{41}$. This combination is no longer used in most countries.

The pro-coagulant effects of an overactive inflammatory response $^{3}$ can increase the likelihood of thrombosis and embo- $\operatorname{lism}^{44}$. Abnormal coagulation parameters may be present in severely ill patients with COVID-19 and are associated with increased mortality ${ }^{3,44,45}$. D-dimer levels are strongly associated with in-hospital death ${ }^{14}$ along with fibrin degradation product levels with a frequent finding of disseminated intravascular coagulation $^{3,46}$.

Anticoagulation appears to have a critical role according to recent data ${ }^{28}$.

\section{Sequential organ failure assessment score}

The Sequential Organ Failure Assessment (SOFA) score is a mortality prediction score that is based on the degree of dysfunction of six organ systems $s^{47,48}$.

- The score is calculated on admission and every 24 hours until discharge using the worst parameters measured during the prior 24 hours.

- The scores is used in a number of ways.

- As individual scores for each organ to determine progression of organ dysfunction.

- As the sum of scores on one single ICU day.

- As the sum of the worst scores during the ICU stay.

- $\mathrm{Cr}, \mathrm{Bili}, \mathrm{MAP}, \mathrm{GCS}$, platelets, $\mathrm{PaO} 2, \mathrm{FiO} 2$, on mechanical ventilation.

The early detection of multiorgan failure can be an early marker of cytokine storm and mortality prediction or resources use $\mathrm{e}^{49}$

\section{Targeting therapy during the storm}

On top of the most frequent used medications in COVID-19 patients ${ }^{19,50,51}$ dozens of studies have been launched to see whether drugs and devices that block cytokines, or prevent their release in the first place, may keep COVID-19 patients from deteriorating and dying. Many anti-inflammatory agents have already been tested in the prevention of cardiovascular events ${ }^{52}$. Anti-COVID-19 anti-cytokine storm candidates include tocilizumab (Actemra; Roche) and sarilumab (Kevzara; Sanofi/Regeneron), both currently being studied and, could be affective reducing the risk of fatal ventricular tachycardia/fibrillation. Others are anakinra (Kineret ${ }^{\circ}$; Sobi), siltuximab (Sylvant ${ }^{\circ}$; EUSA Pharma) and ruxolitinib (Jafaki ${ }^{\circ}$ Incyte). Numerous studies are examining their effects on IL- 6 and/or IL-1, key actors in the body's response to COVID-19 that can alter heart rhythm and drug absorption. Recently, a preliminary report randomized trial with dexamethasone in severe COVID-19 patients RECOVERY Trial showed a significant reduction in mortality in those receiving oxygen or on invasive mechanical ventilation. (Horby P, Lim WS, Emberson J, et al. Effect of Dexamethasone in Hospitalized Patients with COVID-19: Preliminary Report. medRxiv BMJ Yale. The preprint server for health sciences.doi: https://doi.org/10.1101 /2020.06.22.20137273).

The medical community has so far proposed over 100 clinical trials in severe inflammatory storm including application of mesenchymal stem cells or haemadsorption. https://clinicaltrials.gov/ct2/results?cond=Covid+\&ter$\mathrm{m}=$ inflammation $\& \mathrm{cntry}=\&$ state $=\&$ city $=\&$ dist $=$

\section{Mechanical assist devices and extracorporeal devices in multiorgan failure and shock}

As described earlier, cardiovascular patients are more often affected and compromized by the virus or by the cytokine 


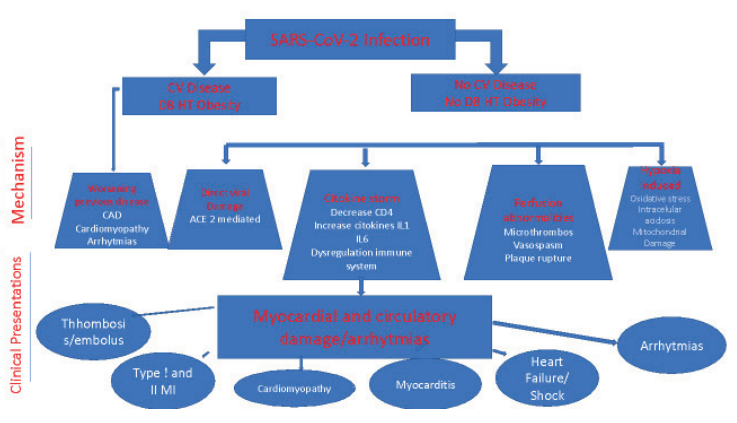

Figure 1. Cardiovascular complications in COVID.

storm, meaning that any ARDS needs to be assessed for cardiovascular involvement as heart failure or mixed shock can be confirmed and measured by physiologic parameters and echocardiography. Shock might be an uncommon but life-threatening complication of a COVID-19 infection. Giving the high number of infections however, an incidence of shock in $6.0 \%$ of all of COVID-19 patients translates in a significant number of patients[53]

A significant number of hospitalized patients with COVID-19 will develop acute respiratory distress syndrome (ARDS) ${ }^{54-56}$. According to one study, $12 \%$ of admitted patients progress to requiring mechanical ventilation with $3 \%$ needing extracorporeal membrane oxygenation (ECMO) support ${ }^{57}$.

Guidelines should stress the importance of performing all other evidence-based interventions, such as lung-protective ventilation and prone positioning, prior to the consideration of $\mathrm{ECMO}^{58}$ (Figure 2). ECMO is a tool of cardiopulmonary support for refractory respiratory and cardiac failure.

There are 2 main types: veno-venous $(\mathrm{V}-\mathrm{V})$ and veno-arterial (V-A). V-V ECMO is used to correct hypoxemia and hypercapnia in isolated lung failure. In one form, a single dual-lumen catheter draws blood from a large vein and reinfuses oxygenated blood back into the right atrium ${ }^{59}$. Another uses 2 cannulas, usually drawing blood from a femoral vein and reinfusing it via the internal jugular vein into the right atrium. Dual-site cannulation is preferred for COVID-19 patients for pulmonary support, as it can be performed safely at the bedside without the need for fluoroscopy or transesophageal echocardiography, so that fewer personnel need to come into the room. V-A-ECMO provides cardiac and circulatory support in addition to oxygenation ${ }^{60}$.

Nonrandomized studies, case series, and reports of using ECMO as a bridge to recovery in ARDS during the 2009 influenza A (H1N1) epidemic suggest that the mortality rate is lower with $\mathrm{ECMO}^{61}$. However, in the ECMO to Rescue Lung Injury in Severe ARDS (EOLIA) trial, the largest trial to date of early use of ECMO in severe ARDS, Coombes et al reported a statistically insignificant $11 \%$ absolute reduction in mortality at 60 days $^{62}$.

Reports from China with ECMO didn't show benefit although no control studies were undertaken ${ }^{1,8,20,63}$.

In cardiovascular patients it is important to determine first whether left-sided cardiac dysfunction is present. Timely

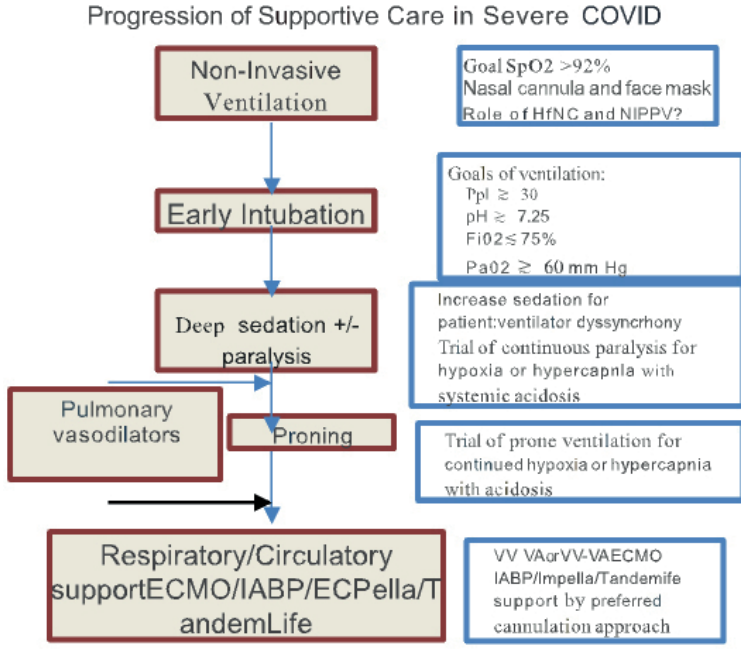

Figure 2.

echocardiographic assessment in the presence of any clinical suspicion of cardiac dysfunction or sign of circulatory compromise should be undertaken ${ }^{53,58,64}$. Pulmonary arterial catheters (PA cath) are helpful for measurements of blood flow, filling pressures as well as for blood gas values from different circulatory compartments.

In high cardiac output states V-A access alone may not be sufficient and eventually a modifications to a hybrid constellation may be indicated (Hybrid ECMO like V-V-A) Shekar K.

Few cases with cardiopulmonary failure were reported using cardiopulmonary support during COVID ${ }^{65,66}$. A myocarditis case in a cardiogenic shock patient that required V-A-EC$\mathrm{MO}$, was reported where a endomyocardial biopsy was undertaken and the virus located in the myocardium for the first time ${ }^{23}$.

A recent case reported in a patient with combined cardiogenic and vasoplegic shock using V-A-ECMO and intravascular microaxial blood pump (CP Impella, Abiomed) with the rational to decrease afterload and to increase organ perfusion by increasing pump power and left ventricular unloading with the Impella and V-A-ECMO devices also by reducing the V-A-ECMO related increase in afterload ${ }^{66}$.

Regardless of whether the systemic arterial hypotension is thought to be cardiogenic with LV failure, distributive, or mixed shock, the LVEF generally is a useful index to determine whether mechanical circulatory support (MCS) is reasonable. If LVEF is high or even normal in the setting of systemic arterial hypotension, the LVEDV and heart rate are normal, then the cardiac output is normal or elevated, and MCS would have to be able (with native output) to exceed that in order to have a hemodynamic benefit. In contrast, if the LVEF is low, then for a normal LVEDV and heart rate, the cardiac output is reduced despite optimal LV preload, and MCS may be reasonable. If the LVEF is reduced, and high doses of inotropes are required to treat systemic arterial hypotension, MCS for the LV may be appropriate in highly selected patients with COVID19.

If a PA cath can be placed expeditiously in patients with shock, they are recommended for the purposes of definitive diagnostics; from PA catheters, the cardiac output and index, LV power/cardiac power output, as well as the PA pulsatility index. 


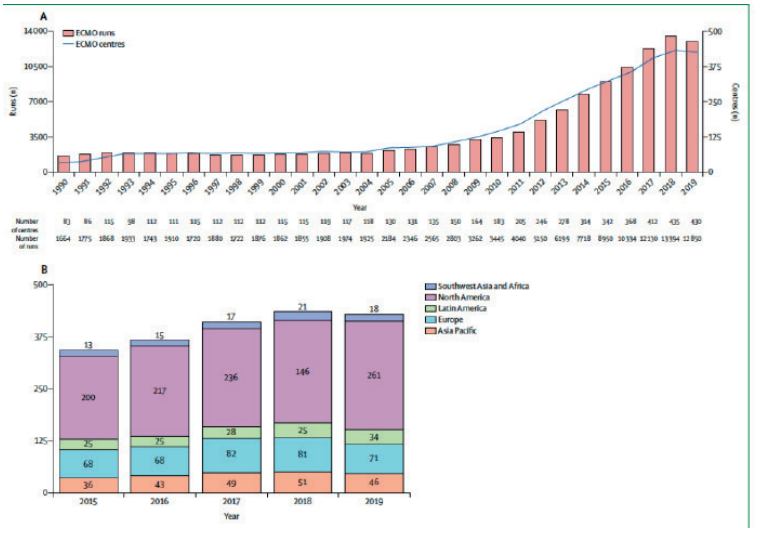

Figure 3. Global ECMO capacity according to ELSO(A) Number of ECMO centres registered with ELSO and number of ECMO runs per year. (B) Geographical distribution of ELSO-registered ECMO centers as of January, 2020. Adapted from the ECMO

Hybrid V-V/V-A ECMO approaches may be reasonable to ensure oxygenation in the upper body. However, hybrid configurations are more complex and resource-intensive, typically requiring continuous bedside attendance.

\section{Short-term left ventricular assist devices with either central or peripheral cannulation; short- term catheter-mounted left ventricular assist devices (Impella ${ }^{\circledR}$, Abiomed)}

The principal advantages of left ventricular assist devices over V-A-ECMO in shock are direct LV unloading, and more homogeneous distribution of blood flow through the systemic arterial circulation. Direct (inflow cannula within the left side of the heart, and particularly the LV) LV unloading is more effective in reduction of LVEDV, and consequently, LV diastolic and systolic pressures; this may be advantageous relative to indirect (inflow cannula proximal to/ upstream of the left side of the heart) unloading (eg, via $\mathrm{V}$-A-ECMO) vis-à-vis greater reduction of pathological load-induced signals and resultant mechanotransduction ${ }^{67}$. The effectiveness of V-A-ECMO in unloading the left side of the heart is an area of some controversy with consistently result in augmentation of the LVEDV and LVEDP. What is less controversial regarding LV distension in V-A-ECMO, is that MCS approaches which employ leftsided circuit inflow (direct unloading) generally are more effective in achieving LV unloading than those which employ right-sided circuit inflow. [67] Consequently, in some patients, left ventricular assist device-based approaches may be superior to V-A-ECMO.

Percutaneous transfemoral placement may be performed at the bedside under echocardiographic guidance, rather than in a cardiac catheterization laboratory. In pandemic conditions, this may be useful. Second, placement via an axillary artery approach, using the newest iteration of introducer sheaths and securing devices may facilitate safer prone positioning. The original Impella 2.5 device generally may not provide adequate flow for the severely compromised shock patient for which robust LV MCS is required. The Impella CP device is better with a peak flow of $4.3 \mathrm{~L} / \mathrm{m}$. The Impella 5.0 and 5.5 devices, each of which may be introduced via side-grafts on the axillary artery, are capable of provi-

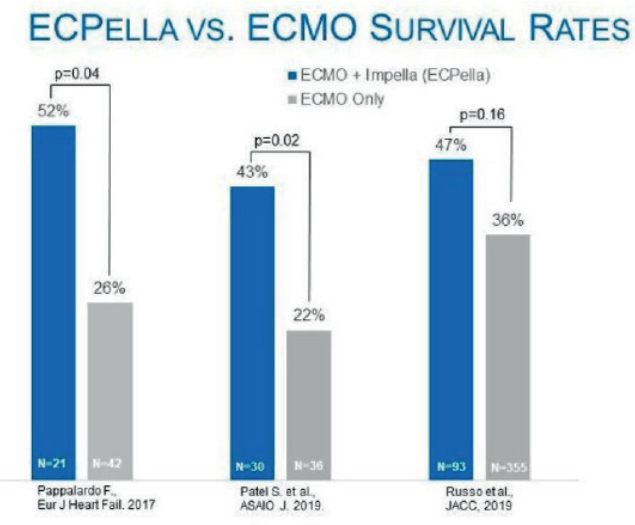

Figure 4. Approximately 10,000 ECMO plus Impella (ECPella) patients with cardiogenic shock over the past 10 years.

ding flows of 5.0 and $5.5 \mathrm{~L} / \mathrm{m}$. respectively, that is, levels of flow close to those achievable with surgically implanted left ventricular assist devices. Experience with Impella in combination with ECMO, that is, "ECPELLA", to enhance unloading and boost support is just beginning to emerge in severly compromised patients with COVID-19.9

\section{RV support respiratory failure commonly causes anincrease in the pulmonary vascular impedance, increasing RV afterload}

In some cases, this can occur to such an extent (afterload mismatch) that even in the setting of normal intrinsic RV contractility, the RVEF and output may decrease substantially (cor pulmonale). In such patients in the acute setting, attempting to treat the underlying etiology of impaired gas exchange using V-V-ECMO alone, may not be sufficient. This is because V-V ECMO recirculation is exacerbated by reduced RVEF and tricuspid regurgitation. In cases of cor pulmonale with COVID-19-related respiratory failure, we suggest that strategies to support the RV are appropriate. For patients who may require proning, percutaneous RVADs using femoro-femoral approaches, can be used with an oxygenator. The single cannula device (eg, Protek Duo, Livanova) approach to this offers the advantages of peripheral cannulation via one site, and with minimal recirculation. Central approaches may be reasonable in patients in whom high flow rates cannot be achieved. If high flow rates are thought not to be achievable with a single cannula approach, then V-V-ECMO plus a device such as the Impella RP may be reasonable.

Because outcomes are clearly poorer when more organ systems are dysfunctional, we suggest that MCS ought to be highly selectively implemented in patients infected with $\mathrm{CO}$ VID-19. ECMO is warranted when metrics indicate a high (80\%) risk of mortality with conventional management. These notably include $\mathrm{PaO}_{2} / \mathrm{FI} \mathrm{O}_{2}$ ratio below 100 , despite available optimal care and need to be avoided in inexperienced centers. Is not a therapy to be rushed to the front lines when all resources are stretched during a pandemic ${ }^{53,68}$. Patients without comorbid conditions under age 50 are the highest priority although resources are limited. Standard contraindications apply terminal disease or otherwise highly limited life expectancy at baseline, active biochemical or clini- 
cal coagulopathy (particularly that which is unable to be treated or has failed treatment), major CNS damage, do not resuscitate (DNR status), and the absence of consent. Exclusions for COVID-19 during limited resources are hospital-specific. Because prognosis is worse, patients with major comorbid conditions (of note is immunosuppression-either due to disease or iatrogenically), age $>70$, and mechanical ventilation $>7$ days, could be reasonably excluded. Anecdotally, renal failure is not an exclusion; however, general outcomes with patients with COVID-19 with renal failure is exceedingly poor in the published Chinese experience ${ }^{69}$.

\section{REFERENCES}

1. Guan WJ, et al. Clinical Characteristics of Coronavirus Disease 2019 in China. NEngl J Med 2020.

2. Liu PP, et al. The Science Underlying COVID-19: Implications for the Cardiovascular System. Circulation 2020.

3. Tang N, et al. Abnormal coagulation parameters are associated with poor prognosis in patients with novel coronavirus pneumonia. J Thromb Haemost 2020.

4. Bonow RO, etal. Association of Coronavirus Disease 2019(COVID-19) With Myocardial Injury and Mortality. JAMA Cardiol 2020.

5. Achenbach J. Medical databases show 1 in 10 hospitalized middle-aged coronavirus patients in U.S. do not survive. The Washington Post 2020.

6. Wang D, et al. Clinical Characteristics of 138 Hospitalized Patients With 2019 Novel Coronavirus-Infected Pneumonia in Wuhan, China. Jama 2020.

7. Huang C, et al. Clinical features of patients infected with 2019 novel coronavirus in Wuhan, China. Lancet 2020;395(10223):497-506.

8. Chen $N$, et al. Epidemiological and clinical characteristics of 99 cases of 2019 novel coronavirus pneumonia in Wuhan, China: a descriptive study. Lancet 2020;395(10223):507-13.

9. Ruan Q, et al. Clinical predictors of mortality due to COVID-19 based on an analysis of data of 150 patients from Wuhan, China. Intensive Care Med 2020

10. Arentz M, et al. Characteristics and Outcomes of 21 Critically III Patients With COVID-19 in Washington State. Jama 2020

11. Madjid M, et al. Potential Effects of Coronaviruses on the Cardiovascular System: A Review. JAMA Cardiol 2020.

12. Matthew J. Cummings, Matthew R. Baldwin, Darryl Abrams, et al. Epidemiology, clinical course, and outcomes of critically ill adults with COVID-19 in New York City: a prospective cohort study. medRXiv BMJ Yale, 2020.

13. Onder G, Rezza G, Brusaferro S. Case-Fatality Rate and Characteristics of Patients Dying in Relation to COVID-19 in Italy. JAMA Online 2020.

14. Grasselli G, Pesenti A, Cecconi M. Critical Care Utilization for the COVID-19 Outbreak in Lombardy, Italy: Early Experience and Forecast During an Emergency Response. Jama 2020.

15. Xu Z, et al. Pathological findings of COVID-19 associated with acute respiratory distress syndrome. Lancet Respir Med 2020.

16. Porcheddu, R., et al., Similarity in Case Fatality Rates (CFR) of COVID-19/ SARS-COV-2 in Italy and China. J Infect Dev Ctries, 2020. 14(2): p. 125-128.

17. Matthew J Cummings, M.M.R.B., MD Darryl Abrams, MD, 1, Epidemiology, clinical course, and outcomes of critically ill adults with COVID-19 in New York City: A prospectivecohort study. The Lancet, 2020. 0(0).

18. Ye, Q. B. Wang, and J. Mao, The pathogenesis and treatment of the 'Cytokine Storm' in COVID-19. J Infect, 2020.

19. Mehra, M.R., et al., Cardiovascular Disease, Drug Therapy, and Mortality in Covid-19. N Engl J Med, 2020.

20. Zhou, F., et al., Clinical course and risk factors for mortality of adult inpatients with COVID-19 in Wuhan, China: a retrospective cohort study. Lancet, 2020

21. Zheng, Y.Y, et al., COVID-19 and the cardiovascular system. Nat Rev Cardiol, 2020.

22. Xiong, T.Y., et al., Coronaviruses and the cardiovascular system: acute and long-term implications. Eur Heart J, 2020.

23. Tavazzi, G., et al., Myocardial localization of coronavirus in COVID-19 cardiogenic shock. Eur J Heart Fail, 2020.

\section{CONCLUSION}

Compared to other hospitalized patients with COVID-19, those needing intensive care, are more likely to have preexisting cardiovascular diseases or risk factors. Cytokine storm with hyperinflammation correlates with the severity of the disease. It is associated with mortality and is a key factor in determining the clinical course of extrapulmonary multiple-organ failure particularly the cardiovascular system. Advanced Cardiac and Pulmonary Support has been reported in selected a COVID population.
24. Alhogbani, T., Acute myocarditis associated with novel Middleeastrespiratory syndrome coronavirus. Ann Saudi Med, 2016. 36(1): p. 78-80.

25. Hu, H., et al., Coronavirus fulminant myocarditis saved with glucocorticoid and human immunoglobulin. Eur Heart J, 2020

26. Lippi, G., C.J. Lavie, and F. Sanchis-Gomar, Cardiac troponin I in patients with coronavirus disease 2019 (COVID-19): Evidence from a meta-analysis. Prog Cardiovasc Dis, 2020

27. Gheblawi, M., et al., Angiotensin Converting Enzyme 2: SARS-CoV-2 Receptor and Regulator of the Renin-Angiotensin System. Circ Res, 2020.

28. Paranipe, I., et al., Association of Treatment Dose Anticoagulation with In-Hospital Survival Among Hospitalized Patients with COVID-19. Journal of the American College of Cardiology, 2020: p. 27327.

29. Shi, S., et al., Association of Cardiac Injury With Mortality in Hospitalized Patients With COVID-19 in Wuhan, China. JAMA Cardiol, 2020.

30. Lala, A., etal., Prevalenceand Impact ofMyocardiallinjuryin Patients Hospitalized with COVID-19 Infection. medRxiv, 2020:p. 2020.04.20.20072702.

31. Du, R.-H., et al., Predictors of Mortality for Patients with COVID-19 Pneumonia Caused by SARS-CoV-2: A Prospective Cohort Study. European Respiratory Journal, 2020: p. 2000524.

32. Chapman, A.R., A. Bularga, and N.L. Mills, High-Sensitivity Cardiac Troponin Can Be An Ally in the Fight Against COVID-19. Circulation. O(0).

33. Hendren, N.S., et al., Description and Proposed Management of the Acute COVID-19 Cardiovascular Syndrome. Circulation, 2020.

34. Ferguson, N.D., et al., The Berlin definition of ARDS: an expanded rationale, justification, and supplementary material. Intensive Care Med, 2012. 38(10): p. 1573-82.

35. Karmpaliotis, D., et al., Diagnostic and prognostic utility of brain natriuretic Peptide in subjects admitted to the ICU with hypoxic respiratory failure due to noncardiogenic and cardiogenic pulmonary edema. Chest, 2007. 131(4):p. 964-71.

36. Green, S.J., Covid-19 accelerates endothelial dysfunction and nitric oxide deficiency. Microbes Infect, 2020.

37. Young, S. and A.P. Fernandez, Skin manifestations of COVID-19. Cleveland Clinic Journal of Medicine, 2020

38. Oxley, T.J., et al., Large-Vessel Stroke as a Presenting Feature of Covid-19 in the Young. New England Journal of Medicine, 2020. 382(20): p. e60.

39. Guo, T., et al., Cardiovascular Implications of Fatal Outcomes of Patients With Coronavirus Disease 2019 (COVID-19). JAMA Cardiol, 2020.

40. Chen, C., Y.Zhou, and D.W. Wang, SARS-CoV-2: a potential novel etiology of fulminant myocarditis. Herz, 2020.

41. Roden, D.M., et al., Considerations for Drug Interactions on QTc in Exploratory COVID-19 (Coronavirus Disease 2019) Treatment. Circulation, 2020.

42. Health, N.I.o., Evaluating the Efficacy of Hydroxychloroquine and Azithromycin to Prevent Hospitalization or Death in Persons With COVID-19. 2020: https://clinicaltrials.gov.

43. Mandeep R Mehra, S.S.D., Frank Ruschitzka, Amit N Patel, Hydroxychloroquine or chloroquine with or without a macrolide for treatment of $\mathrm{CO}$ VID-19: a multinational registry analysis. The Lancet, 2020

44. Fan, B.E., et al., Hematologic parameters in patients with COVID-19 infection. Am J Hematol, 2020.

45. Zhang, Y., et al., Coagulopathy and Antiphospholipid Antibodies in Patients with Covid-19. N Engl J Med, 2020.

46. Cui, S., et al., Prevalence of venous thromboembolism in patients with severe novel coronavirus pneumonia. J Thromb Haemost, 2020. 
47. Vacheron, C.-H., et al., A new simplified and accurate sa-SOFA score. Journal of Critical Care, 2020. 57: p. 240-245.

48. Lambden, S., et al., The SOFA score- development, utility and challenges of accurate assessment in clinical trials. Critical Care, 2019.23.

49. Truog, R.D., C. Mitchell, and G.Q. Daley, The Toughest Triage - Allocating Ventilators in a Pandemic. New England Journal of Medicine, 2020. 382(21): p. 1973-1975.

50. Beigel, J.H., et al., Remdesivir for the Treatment of Covid-19 - Preliminary Report. New England Journal of Medicine, 2020.

51. Cao, B., et al., A Trial of Lopinavir-Ritonavir in Adults Hospitalized with Severe Covid-19. N Engl J Med, 2020. 382(19): p. 1787-1799.

52. Klingenberg, R. and S. Nitschmann, [Colchicine treatment after myocardial infarction: Colchicine Cardiovascular Outcomes Trial (COLCOT)]. Internist (Berl), 2020

53. Bartlett, R.H., et al., Initial ELSO Guidance Document: ECMO for COVID-19 Patients with Severe Cardiopulmonary Failure. Asaio j, 2020. 66(5): p. 472474.

54. Marini, J.J. and L. Gattinoni, Management of COVID-19 Respiratory Distress. JAMA, 2020

55. Luciano Gattinoni, D.C.S.R., COVID-19 pneumonia: ARDS or not? Critical Care, 2020. 24: p. 154

56. Mariusz Kowalewski, D.F., Artur Słomka, Giuseppe Maria Raffa, COVID-19 and ECMO: the interplay between coagulation and inflammation - anarrative review. Critical Care, 2020. 24.

57. Ronco, C., T. Reis, and S. De Rosa, Coronavirus Epidemic and Extracorporeal Therapies in Intensive Care:sivis pacem parabellum. Blood Purif, 2020. 49(3): p. 255-258.

58. Ramanathan, K., et al., Planning and provision of ECMO services for severeARDS during the COVID-19 pandemic and other outbreaks of emerging infectious diseases. Lancet Respir Med, 2020. 8(5): p. 518-526.
59. Rajagopal, K., et al., Advanced Pulmonary and Cardiac Support of COVID-19 Patients: Emerging Recommendations From ASAIO-a Living Working Document. Circ Heart Fail, 2020. 13(5): p. e007175.

60. Khan, R., et al., Utility of extracorporeal membrane oxygenation in COVID-19. Cleveland Clinic Journal of Medicine, 2020.

61. Lim, J.K.B., et al., Extracorporeal Membrane Oxygenation for Severe Respiratory Failure during Respiratory Epidemics and Pandemics: A Narrative Review. Ann Acad Med Singapore, 2020. 49(4): p. 1-34.

62. Combes, A., A.S. Slutsky, and D. Brodie, ECMO for Severe Acute Respiratory Distress Syndrome. N Engl J Med, 2018. 379(11): p. 1091-2.

63. Yang, X., et al., Clinical course and outcomes of critically ill patients with SARS-CoV-2 pneumonia in Wuhan, China: a single-centered, retrospective, observational study. Lancet Respir Med, 2020.

64. Chow, J., et al., Cardiovascular Collapse in COVID-19 Infection: The Role of Veno-Arterial Extracorporeal Membrane Oxygenation (VA-ECMO). CJC Open, 2020.

65. Fried, J.A., et al., The Variety of Cardiovascular Presentations of COVID-19. Circulation, 2020

66. Bemtgen, X., et al., First successful treatment of COVID-19 induced refractory cardiogenic plus vasoplegic shock by combination of p VAD and ECMO - a case report. Asaio j, 2020

67. Rajagopal, K., Left Ventricular Distension in Veno-arterial Extracorporeal Membrane Oxygenation: From Mechanics to Therapies. Asaio j, 2019. 65(1): p. 1-10

68. MacLaren, G., D. Fisher, and D. Brodie, Preparing for the Most Critically III Patients With COVID-19: The Potential Role of Extracorporeal Membrane Oxygenation. Jama, 2020

69. Schmidt, M., et al., Predicting survival after ECMO for refractory cardiogenic shock: the survival after veno-arterial-ECMO (SAVE)-score. Eur Heart J, 2015. 36(33): p. 2246-56. 